\title{
DANDELION
}

postgraduate arts journal \& research network

VOLUME 8 NUMBER I SUMMER 2017

\section{Dossier: Contemporary Methodologies}

TO SUPPLEMENT THIS EDITION'S INVESTIGATION OF THE BAROMETERS OF 'THE Contemporary', Dandelion's editors have decided to include a 'dossier' dedicated to a provisional scanning of contemporary methodologies. The present academic conjuncture appears to be marked by a waning of the dominance of 'high theory', whose various totalizing ambitions have done much to define intellectual study in Humanities departments. This is not to argue that 'theory' is dead, but rather to register the ways its legacies are being reassembled and reconfigured in a multitude of different forms. If the era of 'major' theory might be over-or, at least, temporarily suspended-the Humanities could be considered to have moved into a moment of 'minor', experimental modes of research. Minor, here, is intended in the Deleuzean sense, and represents the multiplication of critical standpoints and an intensification of intellectual strands often left underdeveloped in 'high' theory. Composed by post-Graduate researchers at Birkbeck, the three essays that constitute this 'dossier' hope to illuminate just two of the emerging fields of scholarship: the Digital Humanities and the Medical Humanities. Personal in tone, these essays, through a self-reflexive or meta-critical framework, consider the dilemmas and challenges that confront scholars working within these burgeoning areas of study.

In her essay 'Memes, Magic and What it all Means', Hannah Barton gracefully outlines the difficulties and surprises of working within an area whose coordinates are in constant flux. Tracing the valences of internet memes, from a subcultural practice spawned in 'outsider' forums to their popular hegemonization in media discourse-emphatically crystalized in the United 
States 2016 presidential campaign-the essay notes how the accelerated 'turnover' times of internet culture impacts on academic research. If memes could formerly be dismissed as trivial effluvia-the waste products of cultural exhaustion-they are now, undeniably, an integral part of social identification and political debate. Barton illustrates this process through the metastasis of 'Pepe the Frog', whose passage from the alienated margins to mainstream appropriation back to Fascist 'capture', offers a parable of discursive struggle. Scholars working within Digital Humanities, Barton suggests, are confronted with a mediascape undergoing 'permanent revolution', whose objects mutate from cultural curiosity to politically mediated code with rapidity.

Jan Nawrocki opens 'Methodology in the Medical Humanities: A Short Narrative of Theory and Practice' by recounting their surprise when first confronted with the term 'Medical Humanities'. What follows is an eloquent reconstruction of the moments of intersection between medical study and humanist scholarship. Cutting through the old binary oppositions between theory and practice, Nawrocki advocates Gilles Deleuze's description of theory as a 'well-used box of tools' as a way of framing the procedures of the Medical Humanities. From such a perspective, the doctor-patient relation might be considered in terms of a 'narrative mode', whose focus is not abstract generalizations-although these are clearly still important in relation to physiology - but in the careful elucidation of the narrative of a singular patient, whose stories then guide the doctor. Nawrocki reminds us that medical education is an ongoing form of development, situated on multiple boundaries of knowledge: an education that depends on continuity and experimental experience.

Maria Patsou's essay 'Researching Theatre and Mental Illness' reprises the theme of ongoing evolution within one's chosen academic field, and discusses the need for the researcher to be alert to the sliding frames and shifting borders of transdisciplinary study. For Patsou the Medical Humanities can be framed by the dialectical imperative to acculturate medicine and medicalize humanities; something that Patsou pursues through the imbrication of drama and mental health. Patsou dramatizes the questions that confront the Medical Humanities researcher by focusing on the four components that structure her working methodology.

Hopefully, the dossier will serve as a primer for researchers curious about the Digital and Medical Humanities, and will provide a reference point for scholars trying to work through the complexities encountered with such kaleidoscopic disciplines. 